\title{
One-year rehospitalisation after percutaneous coronary intervention: a retrospective analysis
}

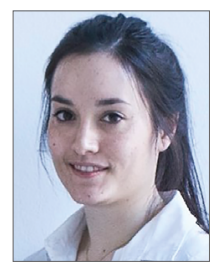

Kirstine Nørregaard Hansen ${ }^{1}$, MD; Kristoffer Bendix ${ }^{1}$, MD; Lisbeth Antonsen ${ }^{1}, \mathrm{MD}, \mathrm{PhD}$; Karsten Tange Veien ${ }^{1}, \mathrm{MD}$; Michael Mæng ${ }^{2}$, MD, PhD; Anders Junker ${ }^{1}, \mathrm{MD}, \mathrm{PhD}$;

Evald Høj Christiansen², MD, PhD; Johnny Kahlert ${ }^{3}$, MSc;

Christian Juhl Terkelsen², MD, DMSci, PhD; Lotte Brix Christensen³, MSc;

Christian Oliver Fallesen ${ }^{1}, \mathrm{MD}$; Hans Erik Bøtker ${ }^{2}, \mathrm{MD}$, DMSci, PhD;

Lisette Okkels Jensen ${ }^{1 *}, \mathrm{MD}, \mathrm{DMSci}, \mathrm{PhD}$

1. Department of Cardiology, Odense University Hospital, Odense, Denmark; 2. Department of Cardiology, Aarhus University

Hospital, Aarhus, Denmark; 3. Department of Clinical Epidemiology, Aarhus University, Aarhus, Denmark

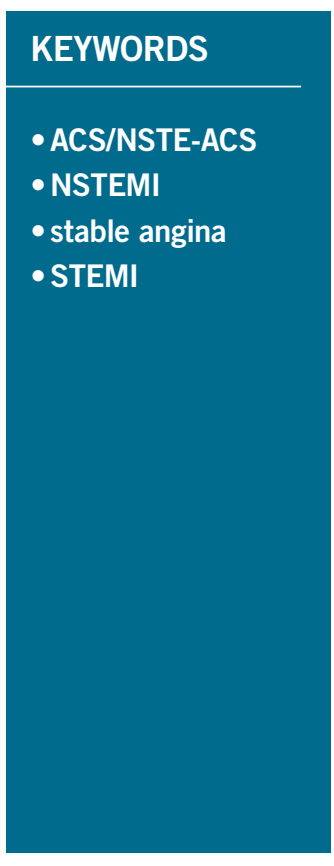

\begin{abstract}
Aims: The aim of the study was to evaluate the incidence and causes of rehospitalisation within one year after percutaneous coronary intervention (PCI) in a country where the National Health Service provides universal tax-supported healthcare, guaranteeing residents free hospital access.
\end{abstract}

Methods and results: Between January 2010 and September 2014, 17,111 patients were treated with PCI in two University Hospitals in Western Denmark. Patients who were readmitted within one year after PCI were identified. The overall one-year readmission rate was $50.4 \%$. The cause was angina/myocardial infarction (MI) in 4,282 patients (49.7\%), and other reasons in 4,334 (50.3\%). Predictors of angina/MI-related readmissions were female gender (odds ratio [OR] 1.15, 95\% confidence interval [CI]: 1.07-1.25), diabetes (OR 1.14, 95\% CI: 1.04-1.26), age (per 10-year increase) (OR 0.86, 95\% CI: 0.83-0.88), and indication for index PCI (stable angina pectoris as reference): ST-segment elevation myocardial infarction (OR 1.34, 95\% CI: 1.23-1.47) and non-ST-segment elevation myocardial infarction (OR 1.18, 95\% CI: 1.08-1.29). Predictors for other readmissions were female gender (OR 1.09, 95\% CI: 1.01-1.18), diabetes (OR 1.29, 95\% CI: 1.18-1.42), age (OR 1.30, 95\% CI: 1.26-1.34) and Charlson comorbidity index $\geq 3$ (OR 3.03, 95\% CI: 2.71-3.27).

Conclusions: In an unselected patient cohort treated with PCI, half of the patients were rehospitalised within one year, highlighting the impact of comorbidity in patients with ischaemic heart disease.

\footnotetext{
*Corresponding author: Department of Cardiology, Odense University Hospital, Sdr. Boulevard 29, 5000 Odense C, Denmark. E-mail: okkels@dadlnet.dk
} 


\section{Abbreviations}

$\begin{array}{ll}\text { ACS } & \text { acute coronary syndrome } \\ \text { CABG } & \text { coronary artery bypass graft } \\ \text { CCI } & \text { Charlson comorbidity index } \\ \text { CHF } & \text { chronic heart failure } \\ \text { CI } & \text { confidence interval } \\ \text { IHD } & \text { ischaemic heart disease } \\ \text { MI } & \text { myocardial infarction } \\ \text { NSTEMI } & \text { non-ST-segment elevation myocardial infarction } \\ \text { OR } & \text { odds ratio } \\ \text { PCI } & \text { percutaneous coronary intervention } \\ \text { SAP } & \text { stable angina pectoris } \\ \text { STEMI } & \text { ST-segment elevation myocardial infarction } \\ \text { WDHR } & \text { Western Denmark Heart Registry }\end{array}$

\section{Introduction}

Ischaemic heart disease (IHD) is a progressive condition which can lead to an increased risk of mortality and morbidity ${ }^{1}$. It is a common and burdening condition for both the patients and the healthcare system ${ }^{2,3}$. Initially, patients with coronary artery disease have a relatively low mortality rate (1.2-2.4\%), but the individual prognosis is highly influenced by various factors, such as baseline characteristics, previous myocardial infarction (MI), and comorbid diseases such as diabetes and chronic kidney disease ${ }^{4}$.

Half of the patients presenting with IHD and acute coronary syndrome (ACS) suffer from chronic comorbidities, which may have a major influence on a patient's outcome both during and after hospitalisation ${ }^{1,5}$. It is important to bear in mind various factors such as age, comorbidities and physical condition, when reperfusion with thrombolysis or revascularisation with percutaneous coronary intervention (PCI) or coronary artery bypass graft (CABG) is considered ${ }^{4,5}$. PCI is a common and low-risk procedure with a poorly described readmission pattern ${ }^{6}$.

Thirty-day readmission rates after PCI range from $8.0 \%$ to $17.9 \%$ with a majority of cardiac-related reasons for rehospitalisation, but long-term readmission rates and non-cardiac reasons are poorly described ${ }^{6-10}$. It is difficult to predict long-term readmission, as knowledge of this health issue is limited, but individual health condition has a great influence on the risk of readmission, and needs to be considered when discussing this issue $e^{7,11,12}$. It is important to understand the reasons for readmission to improve patient outcome and prevent readmissions. To shed light on the impact of comorbidity in a progressive condition such as IHD, a long-term investigation of risk factors is necessary.

The purpose of this study was to investigate the one-year readmission rate after PCI and to evaluate predictors for angina/ MI-related and other rehospitalisations in a country with free access to healthcare.

\section{Methods \\ STUDY POPULATION}

The study was conducted using Western Denmark's healthcare databases, which cover the region's entire population of approximately
3.0 million inhabitants (55\% of the Danish population). A detailed description of the databases has been reported previously ${ }^{13}$. The Danish National Health Service provides universal tax-supported healthcare, guaranteeing residents free access to general practitioners and hospitals. We used the Western Denmark Heart Registry (WDHR) to identify all PCI procedures performed from 1 January 2010 up to 30 September 2014, at Odense University Hospital and Aarhus University Hospital. The study protocol was approved by The Danish Data Protection Agency (2012-41-0164).

All Danish citizens can be tracked in the healthcare system and national registries. The Danish Civil Registration System has kept electronic records on gender, birth date, residence, and emigration date since 1968, and characteristics of all non-psychiatric inpatient admissions since 1977 with daily updates ${ }^{14}$. The 10-digit civil registration number assigned at birth and used in all registries allows accurate record linkage ${ }^{15}$. The Danish Civil Registration System provided vital status data for our study participants and minimised loss to follow-up.

\section{DATA ANALYSIS}

PCI procedures were linked to the Danish Civil Registration System using the 10-digit civil registration number, which made it possible to list the readmissions within one year, and to track the diagnoses given during the readmission, specified using ICD-10 coding. Several diagnoses were given during the hospitalisation, but only one action diagnosis was given at discharge. The action diagnosis was used as the reason for readmission. Admissions within two days of the index procedure were interpreted as transfer between departments and were not included as readmissions in the data set. Patients who were readmitted several times within one year were only included once in the data set with the first given diagnosis. Only hospital readmissions were included.

For each patient, data on all diagnoses from the Danish National Registry of Patients were obtained. Comorbidity scores were computed using the Charlson comorbidity index $(\mathrm{CCI})^{16}$, which covers 19 major disease categories, including diabetes mellitus, heart failure, cerebrovascular diseases, and cancer. The CCI is used to estimate risk of death in patients with comorbid diseases. The CCI value is a weighted summary of the diagnoses and weights the number and seriousness of comorbid diseases calculated on the basis of one-year mortality associated with each disease in the original Charlson data set ${ }^{16}$. A modified CCI was used, as diabetes mellitus was considered a separate confounder and removed from the CCI. Reasons for readmission were recorded and categorised.

\section{STATISTICAL ANALYSIS}

Contingency tables were created for the main study variables characterising patients readmitted to hospital and not readmitted after PCI. The group of readmitted patients was further divided into patients with and without diagnoses of IHD. The follow-up period was 365 days after PCI. Statistical comparisons were undertaken for the two readmitted patient groups versus the non-readmitted group, using t-tests for continuous variables and the $\chi^{2}$ test for categorical 
variables. For readmitted patients, the most frequently occurring diagnosis was identified during readmission and up to one year after PCI. Kaplan-Meier curves were constructed to estimate the probability of readmission within 365 days from the PCI and compared across indications for PCI (stable angina pectoris [SAP], STEMI, NSTEMI and other), comorbidities (using CCI ten years prior to PCI), diabetes mellitus and gender with log-rank tests. Eventually, potential risk factors for readmission after PCI were analysed using logistic regression: the indication for PCI, comorbidities, diabetes mellitus together with age and gender. All data analyses were carried out using SAS software, version 9.2 (SAS Institute Inc., Cary, NC, USA).

\section{Results}

\section{STUDY POPULATION}

A total of 18,025 patients were treated with PCI at one of the two participating PCI centres between January 2010 and September 2014. Of these, 158 patients were foreign citizens, 14 patients emigrated, 566 patients died before hospital discharge and $176 \mathrm{had}$ missing admission dates in the database; these were all excluded from the analysis (Figure 1). Thus, the final study cohort consisted of 17,111 patients. The readmissions included both acute readmissions and staged revascularisation. Of the included patients, 8,616 patients $(50.4 \%)$ were readmitted to the hospital within 365 days after the index PCI procedure. The all-cause 30-day readmission rate was $14.9 \%$. The majority of patients were readmitted within the first month (Figure 2).

\section{CHARACTERISTICS OF READMITTED PATIENTS}

The clinical characteristics at baseline are shown in Table 1. Compared with patients who were not readmitted, females, smokers

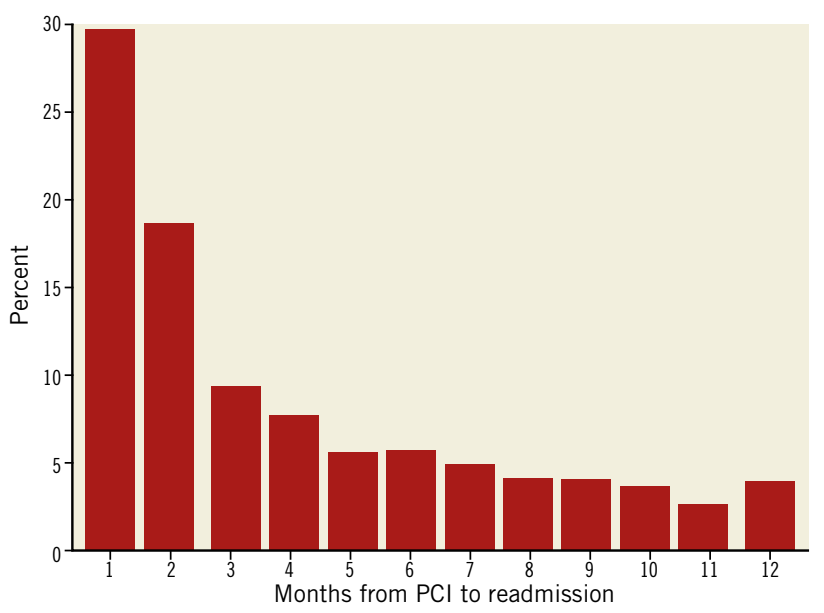

Figure 2. Timing of all-cause rehospitalisation: non-cumulative frequency within one year.

and diabetics were more likely to be readmitted for angina/MI. However, patients readmitted due to other reasons were more likely to be elderly, female, have a family history of IHD, hypertension, hypercholesterolaemia, diabetes mellitus, and have higher levels of creatinine, compared to patients who were not readmitted. Patients with previous PCI, or CABG, or MI patients with comorbidities, with a longer stay at index hospitalisation, and patients with multivessel disease were more likely to be readmitted within 365 days, no matter the reason. The frequency of each component of the modified CCI is illustrated in Figure 3. The most common comorbidities were MI, peripheral vascular disease and cerebrovascular disease.

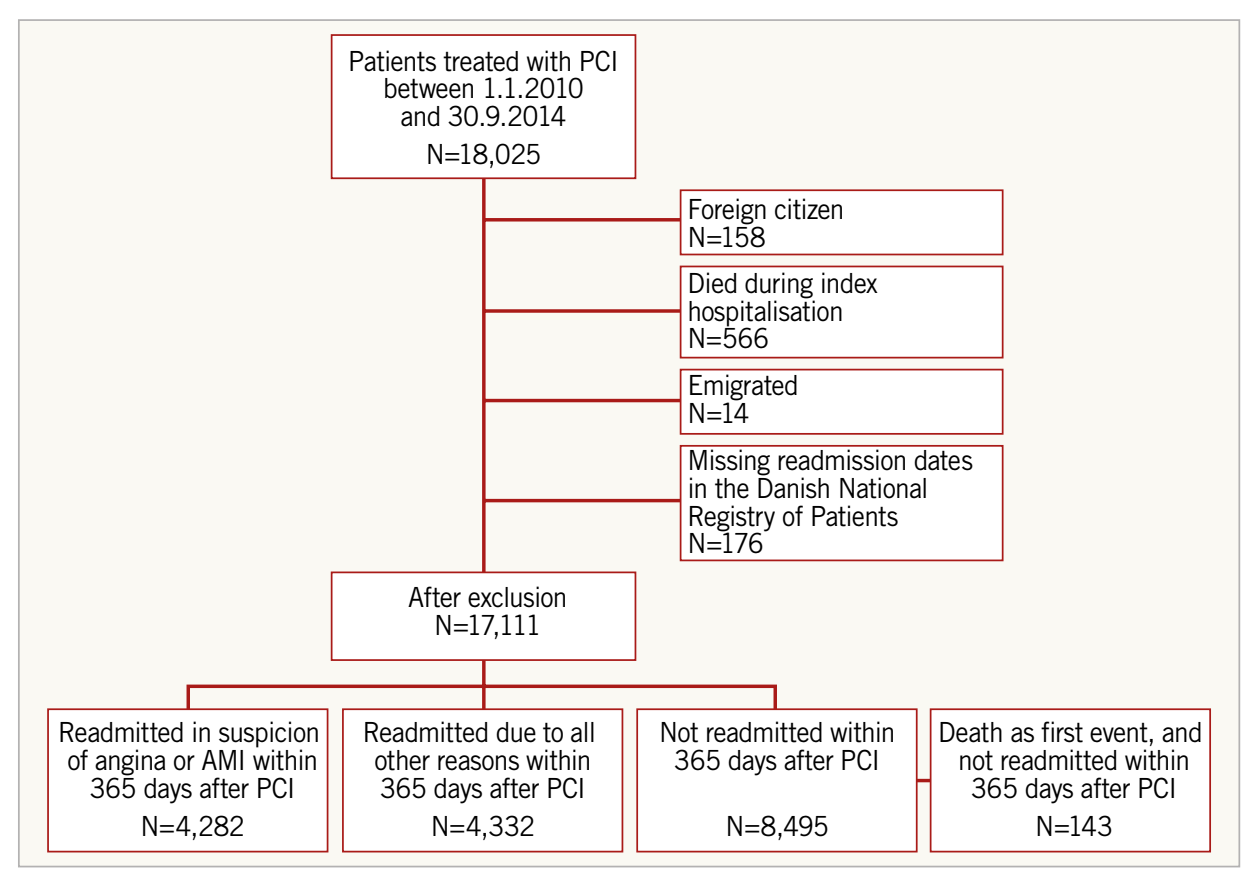

Figure 1. Flow chart of enrolled patients. 
Table 1. Baseline characteristics of patients readmitted to hospital within 365 days after a $\mathrm{PCI}$ procedure $(\mathrm{N}=17,111)$.

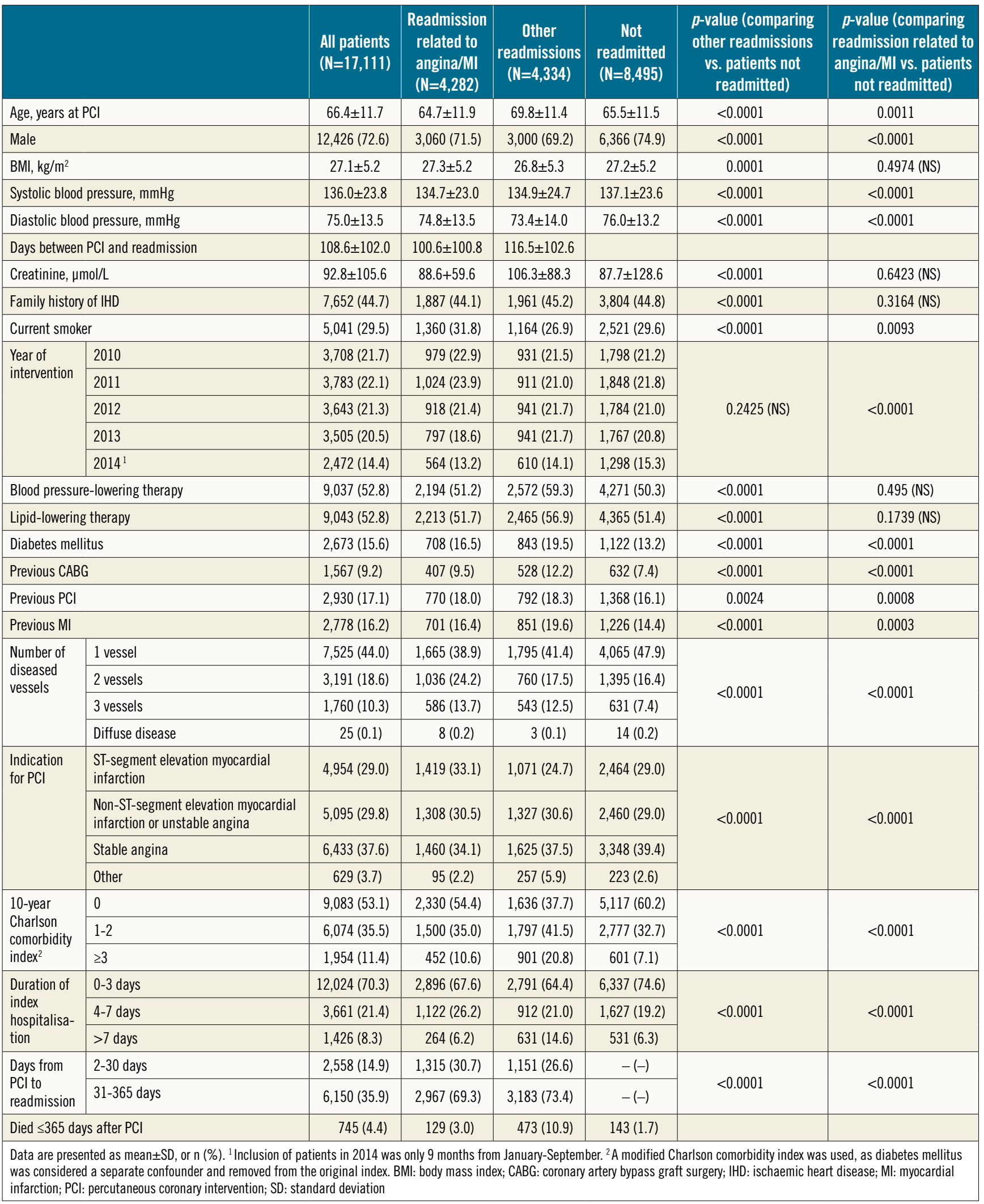

\section{REASONS FOR READMISSION}

Reasons for readmission were various and are shown in Table 2. Of all the 8,616 patients readmitted, 4,282 patients $(49.7 \%)$ were readmitted on suspicion of angina/MI within 365 days after the index PCI procedure. The diagnoses defining angina/MI are shown in Table 2. The remaining 4,334 patients (50.3\%) were readmitted 


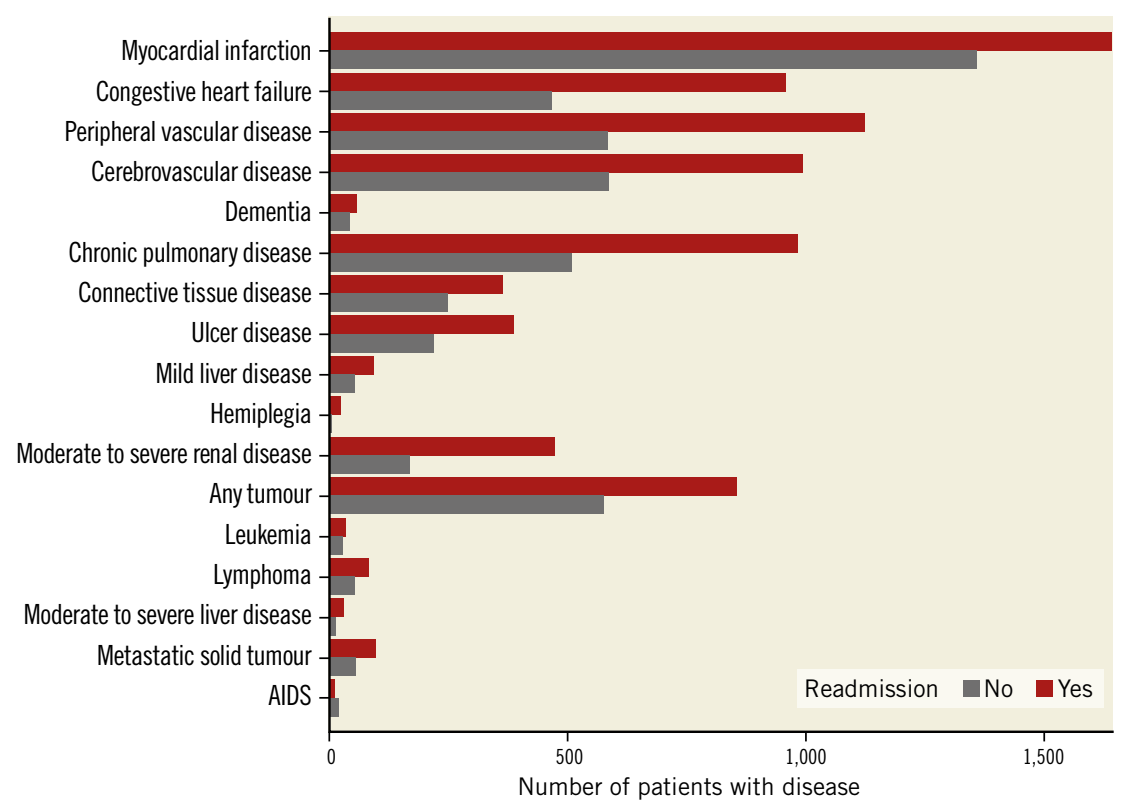

Figure 3. Frequency of each component of the modified Charlson comorbidity index. Note that diabetes is considered a separate confounder and is excluded from the index.

due to other indications. The most common angina/MI-related reasons for readmission were angina pectoris/chest pain $(87.5 \%)$ and ACS (12.5\%). ACS is defined by the action diagnosis: MI, unspecified, unstable angina, STEMI and NSTEMI. For patients readmitted for other reasons, heart failure was the most common cause $(5.5 \%)$, followed by atrial fibrillation/flutter $(5.3 \%)$, and abdominal pain (5.3\%) (Table 2).

A

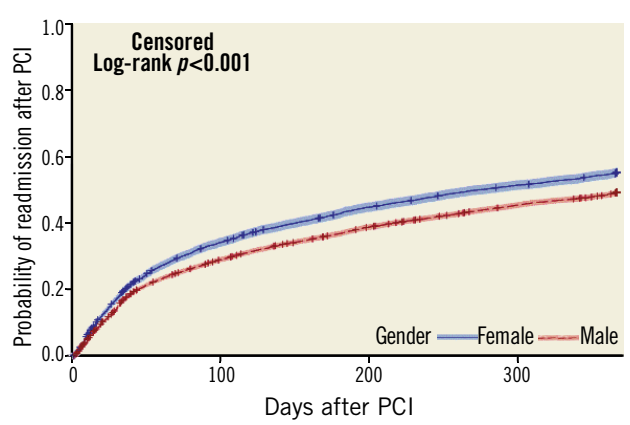

C

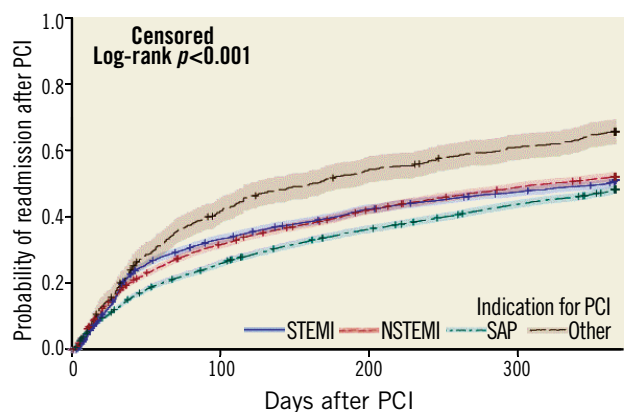

\section{RISK OF READMISSION}

The probability of readmission is illustrated in the KaplanMeier curves (Figure 4). The probability of being readmitted within 365 days increased with higher modified 10-year CCI, if the patients were diabetic or female, or if the PCI was performed due to an indication other than NSTEMI, STEMI or SAP.

B

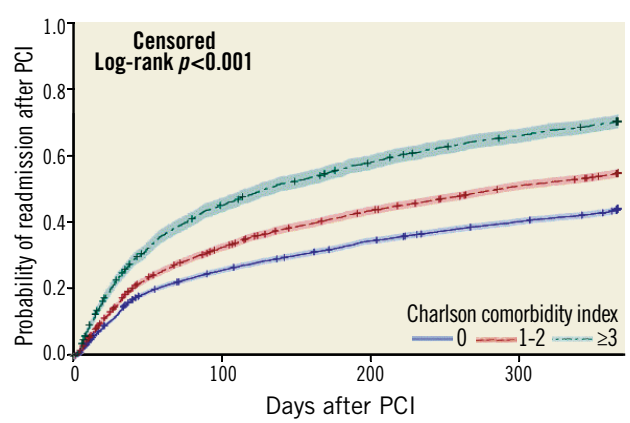

D

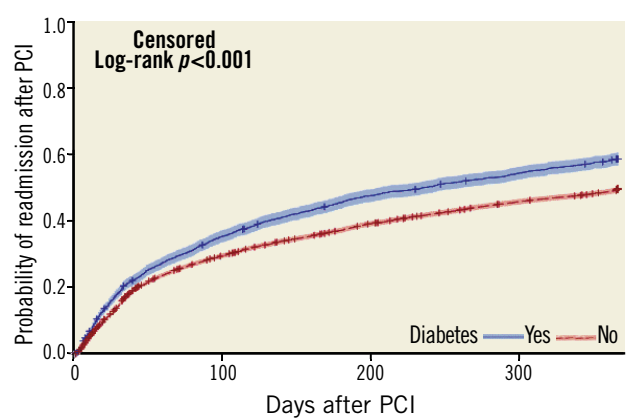

Figure 4. Kaplan-Meier cumulative event curves with $95 \%$ confidence limits for probability of readmission after PCI within a year as per various factors. A) Gender. B) Modified Charlson comorbidity index. C) Indication for percutaneous coronary intervention. D) Diabetes status. 
Table 2. Causes of readmission for the first readmission within 365 days after $\mathrm{PCl}$.

\begin{tabular}{|c|c|c|}
\hline \multicolumn{3}{|c|}{ Angina/Ml-related readmissions. $\mathrm{N}=4,282$} \\
\hline & Diagnosis & $\mathbf{N}(\%)$ \\
\hline 1 & Angina pectoris/chest pain & $3,746(87.5 \%)$ \\
\hline 2 & Acute coronary syndromes & $536(12.5 \%)$ \\
\hline \multicolumn{3}{|c|}{ Top 25 other readmissions. $N=4,334$} \\
\hline & Diagnosis & $\mathbf{N}(\%)$ \\
\hline 1 & Heart failure & $240(5.5 \%)$ \\
\hline 2 & Atrial fibrillation/flutter & $231(5.3 \%)$ \\
\hline 3 & $\begin{array}{l}\text { Abdominal pain, cholecystitis, colitis, } \\
\text { enteritis, pancreatitis, cholangitis and } \\
\text { appendicitis }\end{array}$ & $231(5.3 \%)$ \\
\hline 4 & Cancer & $218(5.0 \%)$ \\
\hline 5 & Bleeding & $201(4.6 \%)$ \\
\hline 6 & Sepsis/bacterial infections & $194(4.5 \%)$ \\
\hline 7 & Pneumonia & $191(4.4 \%)$ \\
\hline 8 & Arthritis, arthrosis and joint pains & $171(3.9 \%)$ \\
\hline 9 & Fractures, lesions and contusion & $167(3.9 \%)$ \\
\hline 10 & Valve disease & $161(3.7 \%)$ \\
\hline 11 & Arrhythmia & $157(3.6 \%)$ \\
\hline 12 & Peripheral vascular disease & $154(3.6 \%)$ \\
\hline 13 & Dyspnoea/respiratory insufficiency & $139(3.2 \%)$ \\
\hline 14 & Suspected condition & $135(3.1 \%)$ \\
\hline 15 & Syncope & $119(2.7 \%)$ \\
\hline 16 & Anaemia & $118(2.7 \%)$ \\
\hline 17 & Kidney failure/disease & $105(2.4 \%)$ \\
\hline 18 & Neurological symptoms & $103(2.4 \%)$ \\
\hline 19 & Hypertension and other cardiac conditions & $93(2.1 \%)$ \\
\hline 20 & Ischaemic stroke & $89(2.1 \%)$ \\
\hline 21 & Chronic obstructive pulmonary disease & $80(1.8 \%)$ \\
\hline 22 & Heart/valve transplantation & $66(1.5 \%)$ \\
\hline 23 & Complication after other procedures & $63(1.5 \%)$ \\
\hline 24 & Benign tumour & $60(1.4 \%)$ \\
\hline 25 & Dehydration & $50(1.3 \%)$ \\
\hline & Other & $798(18.4 \%)$ \\
\hline
\end{tabular}

A modified 10-year $\mathrm{CCI} \geq 3$ was the strongest risk factor for other readmission (OR 3.0, 95\% CI: 2.7-3.3, p<0.0001) (Table 3) but did not increase the risk for angina/MI patients. Patients presenting with NSTEMI and STEMI were at no greater risk of being readmitted for other reasons compared to patients with SAP, whereas patients with other indications for PCI had a 2.7-fold increased risk for other readmissions than those with stable angina. However, both NSTEMI and STEMI patients had a higher risk of angina/MI-related readmission compared to SAP, while other indications for PCI were associated with a lower likelihood of angina/ MI-related readmission. Older age was linked to a 1.3 times higher risk of other readmission but was associated with a lower likelihood of angina/MI-related readmission. Females and diabetic patients had a slightly higher risk of readmission in both groups.

\section{ANGIOGRAM AND REVASCULARISATION}

Of the 17,111 patients included in the study, 3,455 (20.2\%) had new coronary angiography within 365 days after index PCI (Table 4). The coronary angiography was followed by PCI in

\section{Table 4. Patients with new coronary angiography and} revascularisation within 365 days. $\mathrm{N}=17,111$.

\begin{tabular}{|c|c|}
\hline Patients with new coronary angiography & $3,455(20.2 \%)$ \\
\hline \multicolumn{2}{|l|}{ Patients with new revascularisation } \\
\hline Patients with $\mathrm{PCl}$ & $1,247(7.3 \%)$ \\
\hline Days since $\mathrm{PCl}$ & $119 \pm 113.3$ \\
\hline Patients with $\mathrm{CABG}$ & $166(1.0 \%)$ \\
\hline Days since $\mathrm{PCl}$ & $136 \pm 107.7$ \\
\hline \multicolumn{2}{|l|}{ Patients with staged* revascularisation } \\
\hline Patients with staged ${ }^{*} \mathrm{PCl}$ & $658(3.8 \%)$ \\
\hline Days since $\mathrm{PCl}$ & $37 \pm 47.6$ \\
\hline Patients with staged $\mathrm{CABG}$ & $282(1.6 \%)$ \\
\hline Days since $\mathrm{PCl}$ & $78 \pm 57.0$ \\
\hline \multicolumn{2}{|c|}{$\begin{array}{l}\text { Data are presented as mean } \pm \mathrm{SD} \text {, or } \mathrm{n}(\%) .{ }^{*} \mathrm{New} \mathrm{PCl} \text { or } \mathrm{CABG} \\
\text { procedures after index } \mathrm{PCl} \text { performed without new angiogram were } \\
\text { interpreted as staged. CABG: coronary artery bypass graft surgery; } \\
\mathrm{PCl} \text { : percutaneous coronary intervention }\end{array}$} \\
\hline
\end{tabular}

Table 3. Predictors of readmission.

\begin{tabular}{|c|c|c|c|c|c|}
\hline \multirow{2}{*}{ Characteristic } & \multirow{2}{*}{ Comparator } & \multicolumn{2}{|c|}{ Readmissions related to angina/MI } & \multicolumn{2}{|c|}{ Other readmissions } \\
\hline & & Adjusted OR (95\% CI) & $p$-value & Adjusted OR (95\% CI) & $p$-value \\
\hline Sex & Female vs. male & $1.152(1.065-1.246)$ & 0.0004 & $1.088(1.005-1.178)$ & 0.0375 \\
\hline Diabetes mellitus & Yes vs. no & $1.140(1.035-1.256)$ & 0.0078 & $1.293(1.176-1.422)$ & $<0.0001$ \\
\hline Age & Per 10-year increase & $0.855(0.829-0.882)$ & $<0.0001$ & $1.297(1.255-1.341)$ & $<0.0001$ \\
\hline \multirow[t]{2}{*}{$\mathrm{CCl}$} & $1-2$ vs. 0 & $1.055(0.976-1.140)$ & 0.1799 & $1.655(1.528-1.792)$ & $<0.0001$ \\
\hline & $\geq 3$ vs. 0 & $1.038(0.920-1.171)$ & 0.5467 & $3.026(2.713-3.274)$ & $<0.0001$ \\
\hline \multirow[t]{3}{*}{ Presentation } & Other vs. SAP & $0.624(0.497-0.783)$ & $<0.0001$ & $2.705(2.278-3.213)$ & $<0.0001$ \\
\hline & NSTEMI vs. SAP & $1.180(1.082-1.287)$ & 0.0002 & $1.029(0.943-1.122)$ & 0.5271 \\
\hline & STEMI vs. SAP & $1.347(1.234-1.470)$ & $<0.0001$ & $1.039(0.947-1.140)$ & 0.4154 \\
\hline
\end{tabular}

Adjusted for all covariates. CCI: Charlson comorbidity index; Cl: confidence interval; MI: myocardial infarction; NSTEMI: non-ST-elevation myocardial infarction; OR: odds ratio; SAP: stable angina pectoris; STEMI: ST-elevation myocardial infarction 
1,247 patients $(7.3 \%)$, and CABG in 166 patients (1.0\%). Planned revascularisation was seen in $5.5 \%$ of the patients - $658(3.8 \%)$ received staged PCI, and $282(1.6 \%)$ underwent staged CABG.

\section{Discussion}

The present study found that half of the patients undergoing PCI were readmitted within one year after the procedure. Half of the readmitted patients were rehospitalised on suspicion of angina/ MI, and half were readmitted due to other causes. One in eight of the angina/MI patients was hospitalised due to ACS, and the rest were readmitted due to angina or angina-suspected events. The allcause 30-day readmission rate was found to be $14.9 \%$.

A recent published study ${ }^{8}$ found a lower 30-day readmission rate compared to ours $(9.8 \%$ vs. $14.9 \%)$. Multiple aspects can influence the differing results. Firstly, data collection using WDHR combined with the Danish Civil Registration System made it possible to register all readmissions to every Danish hospital and not just the index hospital, thereby minimising loss to follow-up. Secondly, we included PCI centres with patient uptake from Western Denmark, which comprises both metropolitan and rural areas. Additionally, our study included patients from two of five PCI centres, thereby representing half of the Danish population. Furthermore, the patient's possibility of readmission did not depend on health insurance or income due to the free Danish healthcare system, thus resulting in a diverse population.

Our results confirmed that chest pain was the major reason for readmission within the first year after index PCI. Among patients presenting with IHD symptoms, the suspicion of ACS often results in diagnostic procedures such as coronary angiography. Occasionally, angiography was performed for diagnostic or research purposes during readmission, and repeat revascularisations were also performed as elective procedures at times. One fifth of the readmitted patients had a new angiogram, but only a minority required revascularisation treatment with repeat PCI $(7.3 \%)$ or CABG $(1.0 \%)$. In prior studies, approximately half of all readmitted patients underwent a repeat PCI within 30 days of readmission, but only a small percentage $(10.5 \%)$ was due to acute $\mathrm{MI}^{6,17-19}$. Also, in these studies, both staged and acute PCI were encountered. It should be borne in mind that patients are at great risk of repeat revascularisation within the first month after index PCI - often a staged procedure - but this plays a small role in readmission treatment within 365 days $^{20}$.

In order to reduce the readmission rates after PCI, it should be taken into account that the patient's individual condition and health status appear to influence the outcome, more than the PCI procedure itself. IHD is a progressive disease that leads to an increased risk of both mortality and morbidity. Several variables influencing mortality - such as female sex, medical insurance, education and age - are not modifiable $e^{7,17,19}$, but comorbidity may have a greater impact on one-year outcome than was previously expected. Our findings show that half of the patients were readmitted due to other reasons, e.g., infection, cancer, chronic obstructive pulmonary disease, diseased peripheral vessels, chronic heart failure
(CHF) and kidney failure. Patients with a CCI $\geq 3$ had a threefold increased risk of readmission for other reasons, whereas CCI played no significant role for patients readmitted with angina/MI. Furthermore, diabetes and old age increased the readmission risk significantly. Patients with an index indication for PCI other than SAP, STEMI or NSTEMI were at a 2.7-fold increased risk of readmission. This indication covers, for example, revascularisation in patients with arrhythmia, valve disease, cardiomyopathy and $\mathrm{CHF}$ with severely reduced ejection fraction. This group of patients is known to suffer from more comorbidities ${ }^{21}$. Comorbidity in IHD patients is associated with long-term mortality and renal disease, diabetes, peripheral vascular disease and chronic obstructive pulmonary disease in particular lead to higher mortality rates. These findings indicate that chronic medical conditions should be considered when investigating management of individual therapy, counselling and quality comparison to avoid readmission.

Long length of hospital stay was related to higher readmission rates for all readmissions, demonstrating that patients in need of no or limited healthcare after the procedure were less likely to be readmitted. Similar results have been presented in prior studies ${ }^{8,18}$. These findings indicate that patients with comorbidities are at high risk for readmission and are particularly vulnerable after PCI procedures. This information can be used to advise the health system to be careful with treatment and discharge of patients with comorbid diseases, and to consider the benefits from close outpatient follow-up after the index PCI.

\section{Limitations}

Our study should be interpreted in the context of several potential limitations. Firstly, as previously discussed, we did not distinguish between patients who were readmitted more than once within a year; these patients were only included in the data set with their first readmission diagnosis. In addition, readmission within two days of the index procedure was interpreted as transfer between departments or hospitals during the index admission and was not included as a readmission in the data set, thereby risking losing very early, acute readmissions. Secondly, it was not possible to differentiate between patients who underwent coronary angiography for research purposes, or patients undergoing coronary angiography or PCI due to acute chest pain. Thirdly, principal diagnoses such as "chest pain", "chronic heart failure" and "ACS" are defined from several different diagnostic codes, which results in difficulties determining the actual reason for readmission. Finally, in our study, we present data from a population with free healthcare which are thereby not limited by economic aspects. It is unclear therefore to what extent our results can be generalised to other healthcare systems and hospitals.

\section{Conclusions}

In an unselected patient cohort treated with PCI, a substantial proportion of patients is readmitted within one year. The reasons for readmission fall into several broad categories with "chest pain" as the most common diagnosis. Even though one in five patients had 
new angiography, only a minority of the patients needed repeat revascularisation. Other reasons for rehospitalisations accounted for half of the readmissions with a large number of both cardiac and non-cardiac causes. Comorbidities were the strongest predictor of readmission and were associated with an increased risk of readmission, which highlights the impact of comorbidity in patients with IHD.

\section{Impact on daily practice}

In a country with free hospital access, half of the patients undergoing PCI were readmitted within one year after the procedure. Half of the readmitted patients were rehospitalised on suspicion of IHD, and half were readmitted due to non-IHD causes. This information can be used to advise the health system to be careful with treatment and discharge of patients with comorbid diseases, and to consider the benefits of close outpatient follow-up after index PCI.

\section{Conflict of interest statement}

L.O. Jensen has received research grants from Terumo, Biotronik, St. Jude Medical, and Biosensors to her institution. The other authors have no conflicts of interest to declare.

\section{References}

1. Sachdev M, Sun JL, Tsiatis AA, Nelson CL, Mark DB, Jollis JG. The prognostic importance of comorbidity for mortality in patients with stable coronary artery disease. $\mathrm{J} \mathrm{Am} \mathrm{Coll} \mathrm{Cardiol.}$ 2004;43:576-82.

2. Wong ND. Epidemiological studies of CHD and the evolution of preventive cardiology. Nat Rev Cardiol. 2014;11:276-89.

3. Keeley EC, Boura JA, Grines CL. Primary angioplasty versus intravenous thrombolytic therapy for acute myocardial infarction: a quantitative review of 23 randomised trials. Lancet. 2003;361: 13-20.

4. Task Force Members, Montalescot G, Sechtem U, Achenbach S, Andreotti F, Arden C, Budaj A, Bugiardini R, Crea F, Cuisset T, Di Mario C, Ferreira JR, Gersh BJ, Gitt AK, Hulot JS, Marx N, Opie LH, Pfisterer M, Prescott E, Ruschitzka F, Sabaté M, Senior R, Taggart DP, van der Wall EE, Vrints CJ; ESC Committee for Practice Guidelines, Zamorano JL, Achenbach S, Baumgartner H, Bax JJ, Bueno H, Dean V, Deaton C, Erol C, Fagard R, Ferrari R, Hasdai D, Hoes AW, Kirchhof P, Knuuti J, Kolh P, Lancellotti P, Linhart A, Nihoyannopoulos P, Piepoli MF, Ponikowski P, Sirnes PA, Tamargo JL, Tendera M, Torbicki A, Wijns W, Windecker S; Document Reviewers, Knuuti J, Valgimigli M, Bueno H, Claeys MJ, Donner-Banzhoff N, Erol C, Frank H, FunckBrentano C, Gaemperli O, Gonzalez-Juanatey JR, Hamilos M, Hasdai D, Husted S, James SK, Kervinen K, Kolh P, Kristensen SD, Lancellotti P, Maggioni AP, Piepoli MF, Pries AR, Romeo F, Rydén L, Simoons ML, Sirnes PA, Steg PG, Timmis A, Wijns W, Windecker S, Yildirir A, Zamorano JL. 2013 ESC guidelines on the management of stable coronary artery disease: the Task Force on the management of stable coronary artery disease of the European Society of Cardiology. Eur Heart J. 2013;34:2949-3003.

5. Radovanovic D, Seifert B, Urban P, Eberli FR, Rickli H, Bertel O, Puhan MA, Erne P; AMIS Plus Investigators. Validity of Charlson Comorbidity Index in patients hospitalised with acute coronary syndrome. Insights from the nationwide AMIS Plus registry 2002-2012. Heart. 2014;100:288-94.

6. Curtis JP, Schreiner G, Wang Y, Chen J, Spertus JA, Rumsfeld JS, Brindis RG, Krumholz HM. All-cause readmission and repeat revascularization after percutaneous coronary intervention in a cohort of medicare patients. J Am Coll Cardiol. 2009; 54:903-7.

7. Khawaja FJ, Shah ND, Lennon RJ, Slusser JP, Alkatib AA, Rihal CS, Gersh BJ, Montori VM, Holmes DR, Bell MR, Curtis JP, Krumholz HM, Ting HH. Factors associated with 30-day readmission rates after percutaneous coronary intervention. Arch Intern Med. 2012;172:112-7.

8. Wasfy JH, Strom JB, O'Brien C, Zai AH, Luttrell J, Kennedy KF, Spertus JA, Zelevinsky K, Normand SL, Mauri L, Yeh RW. Causes of short-term readmission after percutaneous coronary intervention. Circ Cardiovasc Interv. 2014;7:97-103.

9. Yost GW, Puher SL, Graham J, Scott TD, Skelding KA, Berger PB, Blankenship JC. Readmission in the 30 days after percutaneous coronary intervention. JACC Cardiovasc Interv. 2013;6: 237-44.

10. Yeh RW, Rosenfield K, Zelevinsky K, Mauri L, Sakhuja R, Shivapour DM, Lovett A, Weiner BH, Jacobs AK, Normand SL. Sources of hospital variation in short-term readmission rates after percutaneous coronary intervention. Circ Cardiovasc Interv. 2012;5:227-36

11. Kereiakes DJ. Return to sender hospital readmission after percutaneous coronary intervention. J Am Coll Cardiol. 2009;54: 908-10.

12. Laskey WK, Ricciardi MJ. 30-day readmission rate following percutaneous coronary intervention: much more than a binary variable. JACC Cardiovasc Interv. 2013;6:245-6.

13. Jensen LO, Maeng M, Kaltoft A, Thayssen P, Hansen HH, Bottcher M, Lassen JF, Krussel LR, Rasmussen K, Hansen KN, Pedersen L, Johnsen SP, Sørensen HT, Thuesen L. Stent thrombosis, myocardial infarction, and death after drug-eluting and bare-metal stent coronary interventions. J Am Coll Cardiol. 2007;50:463-70.

14. Andersen TF, Madsen M, Jorgensen J, Mellemkjoer L, Olsen JH. The Danish National Hospital Register. A valuable source of data for modern health sciences. Dan Med Bull. 1999;46:263-8.

15. Pedersen CB, Gotzsche H, Moller JO, Mortensen PB. The Danish Civil Registration System. A cohort of eight million persons. Dan Med Bull. 2006;53:441-9.

16. Charlson ME, Pompei P, Ales KL, MacKenzie CR. A new method of classifying prognostic comorbidity in longitudinal studies: development and validation. J Chronic Dis. 1987;40:373-83.

17. Przybysz-Zdunek B, Ploch M, Pluta W, Dada M, Opolski G. All-cause readmission and repeat revascularization after percutaneous coronary intervention. Cardiol J. 2012;19:174-9. 
18. Hannan EL, Zhong Y, Krumholz H, Walford G, Holmes DR Jr, Stamato NJ, Jacobs AK, Venditti FJ, Sharma S, King SB 3rd. 30-day readmission for patients undergoing percutaneous coronary interventions in New York state. JACC Cardiovasc Interv. 2011;4:1335-42. 19. Meadows ES, Bae JP, Zagar A, Sugihara T, Ramaswamy K, McCracken R, Heiselman D. Rehospitalization following percutaneous coronary intervention for commercially insured patients with acute coronary syndrome: a retrospective analysis. BMC Res Notes. 2012;5:342.
20. Egholm G, Kristensen SD, Thim T, Olesen KK, Madsen M, Jensen SE, Jensen LO, Sorensen HT, Botker HE, Maeng M. Risk Associated With Surgery Within 12 Months After Coronary DrugEluting Stent Implantation. J Am Coll Cardiol. 2016;68:2622-32.

21. Ranasinghe I, Naoum C, Aliprandi-Costa B, Sindone AP, Steg PG, Elliott J, McGarity B, Lefkovits J, Brieger D; AustraliaNew Zealand GRACE. Management and outcomes following an acute coronary event in patients with chronic heart failure 19992007. Eur J Heart Fail. 2012;14:464-72. 